\title{
The vertical structure and spatial variability of lower-tropospheric water vapor and clouds in the trades
}

\author{
Ann Kristin Naumann ${ }^{1,2}$ and Christoph Kiemle ${ }^{3}$ \\ ${ }^{1}$ Max Planck Institute for Meteorology, Hamburg, Germany \\ ${ }^{2}$ Meteorological Institute, Center for Earth System Research and Sustainability (CEN), \\ Universität Hamburg, Hamburg, Germany \\ ${ }^{3}$ Deutsches Zentrum für Luft- und Raumfahrt, Institute of Atmospheric Physics, Oberpfaffenhofen, Germany
}

Correspondence: Ann Kristin Naumann (ann-kristin.naumann@mpimet.mpg.de)

Received: 2 November 2019 - Discussion started: 20 December 2019

Revised: 7 April 2020 - Accepted: 17 April 2020 - Published: 26 May 2020

\begin{abstract}
Horizontal and vertical variability of water vapor is omnipresent in the tropics, but its interaction with cloudiness poses challenges for weather and climate models. In this study we compare airborne lidar measurements from a summer and a winter field campaign in the tropical Atlantic with high-resolution simulations to analyze the water vapor distributions in the trade wind regime, its covariation with cloudiness, and their representation in simulations. Across model grid spacing from $300 \mathrm{~m}$ to $2.5 \mathrm{~km}$, the simulations show good skill in reproducing the water vapor distribution in the trades as measured by the lidar. An exception to this is a pronounced moist model bias at the top of the shallow cumulus layer in the dry winter season which is accompanied by a humidity gradient that is too weak at the inversion near the cloud top. The model's underestimation of water vapor variability in the cloud and subcloud layer occurs in both seasons but is less pronounced than the moist model bias at the inversion. Despite the model's insensitivity to resolution from hecto- to kilometer scale for the distribution of water vapor, cloud fraction decreases strongly with increasing model resolution and is not converged at hectometer grid spacing. The observed cloud deepening with increasing water vapor path is captured well across model resolution, but the concurrent transition from cloud-free to low cloud fraction is better represented at hectometer resolution. In particular, in the wet summer season the simulations with kilometer-scale resolution overestimate the observed cloud fraction near the inversion but lack condensate near the observed cloud base. This illustrates how a model's ability to properly capture the water vapor distribution does not necessarily translate into an
\end{abstract}

adequate representation of shallow cumulus clouds that live at the tail of the water vapor distribution.

\section{Introduction}

Globally moisture fields, unlike temperature fields, are not smooth, but they vary on the regional scale in particular in the lower troposphere, where water vapor values can be large. The distribution of water vapor strongly interacts with the atmospheric circulation through the formation of clouds and convection and through radiation. This interplay has been studied in the tropics at the large scale (e.g., Pierrehumbert, 1995) but is less well understood in the lower tropical troposphere, where humidity is less well quantified from observations (Nehrir et al., 2017; Stevens et al., 2017). One way to fill this gap is with airborne measurements taken during dedicated field campaigns. In this study, we use airborne lidar measurements from two field campaigns in the northern tropical Atlantic to analyze the vertical structure and the spatial variability of water vapor and clouds and their representation in simulations with resolution from hecto- to kilometer scale.

Water vapor has multiple roles in the atmosphere and is closely connected to cloudiness: the boundary layer humidity sets the potential for deep convection and determines cloud amount (e.g., Keil et al., 2008; Vial et al., 2017). As the vertically integrated amount of water vapor approaches its saturation value over the tropical oceans, precipitation sets in and the amount of precipitation in deep convective regions correlates well with the decrease in subsaturation in 
the column (Bretherton et al., 2004; Holloway and Neelin, 2009). The same relation is found to hold within the dry season in the shallow convective regime (Nuijens et al., 2009). On a process level, the vertical distribution of moisture determines the amount and distribution of radiative cooling and can thereby drive large-scale and mesoscale circulations (e.g., Pierrehumbert, 1995; Muller and Bony, 2015; Naumann et al., 2019). Also, the humidity of cloud-free air in the vicinity of a cloud determines the strength of dilution of in-cloud water by entrainment. The strength of this dilution is a long-standing problem in convective parameterizations, a key ingredient of the thermostat and the iris hypothesis, and a popular tuning parameter (Ramanathan and Collins, 1991; Mauritsen et al., 2012; Mauritsen and Stevens, 2015).

The vertical distribution of moisture and small-scale phenomena such as the dilution of clouds by entrainment pose challenges to both modeling and observations. The WALES (WAter vapor Lidar Experiment in Space) lidar is capable of profiling moisture and aerosols, and detecting cloud tops simultaneously with high accuracy and spatial resolution (Wirth et al., 2009). High resolution in vertical profiles is of particular importance in the tropics since sharp moisture gradients at the trade inversion influence radiation locally (Stevens et al., 2017). Measurements with WALES installed on an aircraft can be undertaken in regions of particular interest. In December 2013 and in August 2016 the NARVAL (Next-generation Aircraft Remote sensing for VALidation) campaigns were the first tropical experiments in which an airborne water vapor lidar participated (Stevens et al., 2019). For the two campaigns the German research aircraft HALO (High-Altitude and Long-Range Research Aircraft) sampled the western tropical Atlantic east of Barbados to investigate the interactions between shallow moist convection, moisture distribution, and radiative effects with a state-of-the-art suite of remote sensing instruments and dropsondes.

The close coupling between clouds and water vapor and the capabilities of lidar measurements in the trade wind regime motivate the guiding questions of this study: what are the vertical structure and the spatial variability of water vapor in the trades? How does cloudiness covary with water vapor, and are models able to represent the observed relationship correctly?

In numerical weather prediction, storm-resolving model (SRM) simulations with kilometer-scale grid spacing are common and evaluated frequently (e.g., Bauer et al., 2015). Aiming to better resolve convection with higher resolution, traditional idealized large-eddy model (LEM) simulations lack the ability to represent the mesoscale and large-scale variability of observed cloud fields (Nuijens and Siebesma, 2019). LEM simulations with hectometer-scale grid spacing are now becoming available on large domains with realistic boundary conditions (Heinze et al., 2017; Stevens et al., 2019). These LEM simulations with realistic and varying large-scale states include the interaction with the largescale circulation, and at the same time the subgrid-scale flow is better constrained than in coarse-resolution simulations. Although simulations with hectometer grid spacing still do not have a grid spacing fine enough to represent details of shallow convection, even kilometer-scale simulations are found to reproduce many features, such as the daily cycle in cloud amount and precipitation, better than climate models with convective parameterization (Stevens et al., 2020; Vial et al., 2019). It is an open question whether hectometer- and kilometer-scale simulations with realistic and varying largescale states are able to represent water vapor variability and its covariation with clouds in the trades and whether this ability depends on resolution.

In model simulations convection, due to its stochastic nature, is not expected to trigger in the exact same position and with the exact same timing as in reality. Therefore comparisons between observations from line-shaped research flights and models, where the comparison is based on co-location of the two in space and time, are often of limited use. To bypass the issue of co-location, other means of comparison are needed. We propose comparing model and observations in moisture space; i.e., we sort water vapor profiles from the driest to the wettest profile, to identify differences in the vertical structure of water vapor and its change in moisture space. The depiction of humidity in moisture space is inspired by Bretherton et al. (2005), who compare model results as a function of column relative humidity to illustrate the mechanisms of convective self-aggregation in radiative convective equilibrium. In observations this technique was first used by Schulz and Stevens (2018). With a comparison of observations and simulations in moisture space we avoid relying on co-location but retain the ability to quantify variability at high spatial resolution.

This paper is organized as follows: Sect. 2 describes the observations and model simulations used in this paper. In Sect. 3 we focus on the case study of a research flight on 11 December 2013, which is a case of typical shallow trade wind convection and is also used to explain our methodology in detail. In Sect. 4 we generalize the results of the case study by applying the same methodology to a set of research flights that allow us to analyze the seasonality of the water vapor structure in the trades. Conclusions are given in Sect. 5.

\section{Observations and model simulations}

\subsection{NARVAL winter and summer campaign}

Two NARVAL field studies took place over the tropical Atlantic Ocean east of Barbados (Stevens et al., 2019). The first part of the field study counts eight research flights between 10 and 20 December 2013, and the second part 10 flights between 8 and 30 August 2016. The details of the NARVAL field studies, such as the flight strategy and the instrumentation of the HALO aircraft, are described by Stevens et al. (2019) and Konow et al. (2019). Not all data are useful to 
the same degree for this analysis, as some of the long flights (e.g., the transit flights between Germany and Barbados) are not contained in the modeling domain of the LEM simulations (see Sect. 2.3) and some other days have not been chosen to be modeled with LEM. For the purpose of this study, we limit the available lidar and microwave radiometer data by the criterion of being included in our smallest modeling domain (see Sect. 2.3). The time and domain constraints are given in Table 1.

Basic differences between the winter and the summer trades appear in the cloud layer moisture and thickness (Table 1). While the winter situations are characterized by similar and undisturbed trade wind conditions, the summer flights encountered a significant layer of Saharan dust on 12 and 19 August, the flight on 22 August was close to the intertropical convergence zone (ITCZ), and the flight on $24 \mathrm{Au}-$ gust was close to the tropical storm Garcon (Gutleben et al., 2019).

\subsection{WALES lidar and HAMP radiometer}

The differential absorption lidar WALES is installed pointing downwards on the HALO aircraft, measuring water vapor profiles throughout the tropical troposphere with three on-line laser wavelength positions in the near infrared situated on three water vapor absorption lines of cascading strength (Wirth et al., 2009; Kiemle et al., 2017; Gutleben et al., 2019). The weakest line, specially selected for the tropics, permits accurate profiling of very moist layers below the inversion that tops the cloud layer in the trades, while the stronger two lines provide reliable data of the moisture jump across the inversion and the dry regions above. Backscatter from aerosol and clouds, corrected for extinction by aerosol, is simultaneously measured by a high-spectral-resolution lidar (HSRL) at $532 \mathrm{~nm}$ with a temporal resolution of $1 \mathrm{~s}$, corresponding to a spatial horizontal resolution along the flight route of $210 \mathrm{~m}$ given the typical aircraft speed of $210 \mathrm{~m} \mathrm{~s}^{-1}$ during the summer campaign and a horizontal resolution of $240 \mathrm{~m}$ given an aircraft speed of $240 \mathrm{~m} \mathrm{~s}^{-1}$ during the winter campaign. Flight speed was higher in winter due to a higher average flight altitude. To achieve an acceptable measurement precision of typically $10 \%$ in the cloud layer and above, the water vapor profiles are aggregated across $12 \mathrm{~s}$, or about $2.5 \mathrm{~km}$ in the summer campaign and $2.9 \mathrm{~km}$ in the winter campaign. The vertical resolution is about $250 \mathrm{~m}$ for water vapor and $15 \mathrm{~m}$ for backscatter. Water clouds quickly attenuate the lidar signal such that valid data are only obtained above cloud top, which is visible in the backscatter signals (Fig. 1a). Full profiles are obtained wherever the cloud gaps are larger than $2.5 \mathrm{~km}$. Due to a methodical constraint, water vapor lidar data below $200 \mathrm{~m}$ are not available. The dropsonde profiles show that humidity is relatively constant with height within this layer, which agrees with the assumption of a well-mixed subcloud layer. To calculate the water vapor path (WVP), we therefore extend the measurements at $200 \mathrm{~m}$ down to the surface.

Since our focus is the cloud layer moisture variability, we only use lidar profiles where more than half of the data points below the maximum cloud top height, which is defined by $q_{\mathrm{c}}$ in Table 1, are valid. For example, on 11 December 2013, the cloud layer top height is $3.0 \mathrm{~km}$, and only in $34 \%$ of all lidar profiles are more than half of the data points valid below this height (Fig. 1a). The rest are unavailable due to clouds or laser adjustment phases. We consequently use only one-third of all profiles of this flight (Fig. 1b). This subset still contains small gaps mainly due to clouds, which we fill with the saturation value by assuming saturation wherever the HSRL backscatter coefficient is $>10 \times 10^{-6} \mathrm{~m}^{-1} \mathrm{sr}^{-1}$, which to sufficient approximation defines a water cloud (Kiemle et al., 2017). We deviate from this threshold only in two cases where the clouds are particularly small (on 12 August 2016 we use $5 \times 10^{-6} \mathrm{~m}^{-1} \mathrm{sr}^{-1}$ to compensate for the signal dilution) or large (on $24 \mathrm{Au}-$ gust 2016 we use $15 \times 10^{-6} \mathrm{~m}^{-1} \mathrm{sr}^{-1}$ ). We fill the remaining gaps with the moisture of the nearest-neighbor profile in the horizontal and call this gap-free result the minimum estimate $\left(W^{2}{ }^{2} S_{\min }\right.$; Fig. 1c). In the maximum estimate $\left(W^{2}{ }^{2} S_{\max }\right.$ ) we additionally fill all original cloud shadows down to the lifting condensation level (LCL), i.e., missing data below lidar-detected clouds, with the saturation value. To find the LCL, we use the lidar signals from thin boundary layer clouds as well as dropsonde profiles and auxiliary lidar information such as aerosol and water vapor gradients at the top of the mixed layer. The saturation humidity profiles are calculated from the temperature profiles of nearby dropsondes. Since the thickness of the cloud cannot be determined by the lidar and lower clouds may also exist above the LCL, the maximum estimate gives an upper bound on cloudiness and WVP (defined as the vertically integrated specific humidity without contributions from liquid or ice). Likewise the minimum estimate provides a lower bound on cloudiness and WVP. Consequently, the difference between the minimum and the maximum estimates characterizes to a satisfying extent the uncertainty of our attempt to quantify the lidar moisture distribution within and below the clouds while aiming to obtain a gap-free data curtain needed for the model comparisons. The difference in WVP between WALES $S_{\max }$ and WALES min $_{\text {in }}$ is at maximum $5 \%$ (Fig. 1d). We will show later that the uncertainty in the measured humidity estimate is small compared to the difference between model and observation (see Sect. 3.2). To obtain the cloud fraction, we apply the abovementioned HSRL backscatter coefficient threshold for water clouds onto the $1 \mathrm{~s}$ lidar backscatter curtains, use a similar min-max assumption to account for measurement and methodical uncertainties, and aggregate it into a $12 \mathrm{~s}$ grid along the flight direction.

To understand which part of the moisture space the WALES lidar misses in cloudy environments, we additionally make use of the HAMP (HALO Microwave Package) 
Table 1. Specification of flight domains used in this study.

\begin{tabular}{|c|c|c|c|c|c|}
\hline$t$ in UTC & Domain & $N$ & $p$ in $\%$ & $q_{\mathrm{c}}$ in $\mathrm{g} \mathrm{kg}^{-1}$ & $h_{\mathrm{c}}$ in $\mathrm{km}$ \\
\hline \multicolumn{6}{|l|}{ NARVAL 1} \\
\hline 11 Dec 2013, 16:00-21:00 & $10.0-16.5^{\circ} \mathrm{N}, 58.0-55.0^{\circ} \mathrm{W}$ & 531 & 34.2 & 4.0 & 3.0 \\
\hline 12 Dec 2013, 14:00-15:00, 19:00-20:00 & $14.0-16.5^{\circ} \mathrm{N}, 56.5-48.5^{\circ} \mathrm{W}$ & 526 & 86.5 & 4.0 & 2.8 \\
\hline 14 Dec 2013, 14:00-15:00, 19:00-20:00 & $13.9-16.5^{\circ} \mathrm{N}, 57.2-48.5^{\circ} \mathrm{W}$ & 296 & 48.9 & 4.0 & 2.5 \\
\hline 15 Dec 2013, 16:00-21:00 & $12.0-16.5^{\circ} \mathrm{N}, 57.5-48.5^{\circ} \mathrm{W}$ & 668 & 72.8 & 4.0 & 2.7 \\
\hline 20 Dec 2013, 17:00-18:00 & $13.3-16.5^{\circ} \mathrm{N}, 56.0-51.6^{\circ} \mathrm{W}$ & 168 & 70.3 & 4.0 & 3.0 \\
\hline \multicolumn{6}{|l|}{$N A R V A L 2$} \\
\hline 12 Aug 2016, 13:00-19:00 & $9.5-14.0^{\circ} \mathrm{N}, 55.0-52.0^{\circ} \mathrm{W}$ & 1317 & 69.0 & 6.0 & 1.9 \\
\hline 19 Aug 2016, 13:00-17:00, 20:00 & $13.5-16.0^{\circ} \mathrm{N}, 57.0-48.0^{\circ} \mathrm{W}$ & 1115 & 85.4 & 8.0 & 2.6 \\
\hline 22 Aug 2016, 14:00-15:00, 20:00-21:00 & $10.0-12.8^{\circ} \mathrm{N}, 58.6-51.0^{\circ} \mathrm{W}$ & 279 & 55.9 & 8.0 & 1.8 \\
\hline 24 Aug 2016, 13:00-16:00 & $13.0-14.5^{\circ} \mathrm{N}, 56.5-44.0^{\circ} \mathrm{W}$ & 405 & 51.3 & 9.0 & 1.6 \\
\hline
\end{tabular}

$t$ : time period of analyzed flight; $N$ : number of valid lidar profiles; $p$ : percentage of valid profiles; $q_{\mathrm{c}}$ : water vapor mixing ratio threshold for detecting a cloud top with WALES; $h_{\mathrm{c}}$ : maximum shallow cloud top altitude.
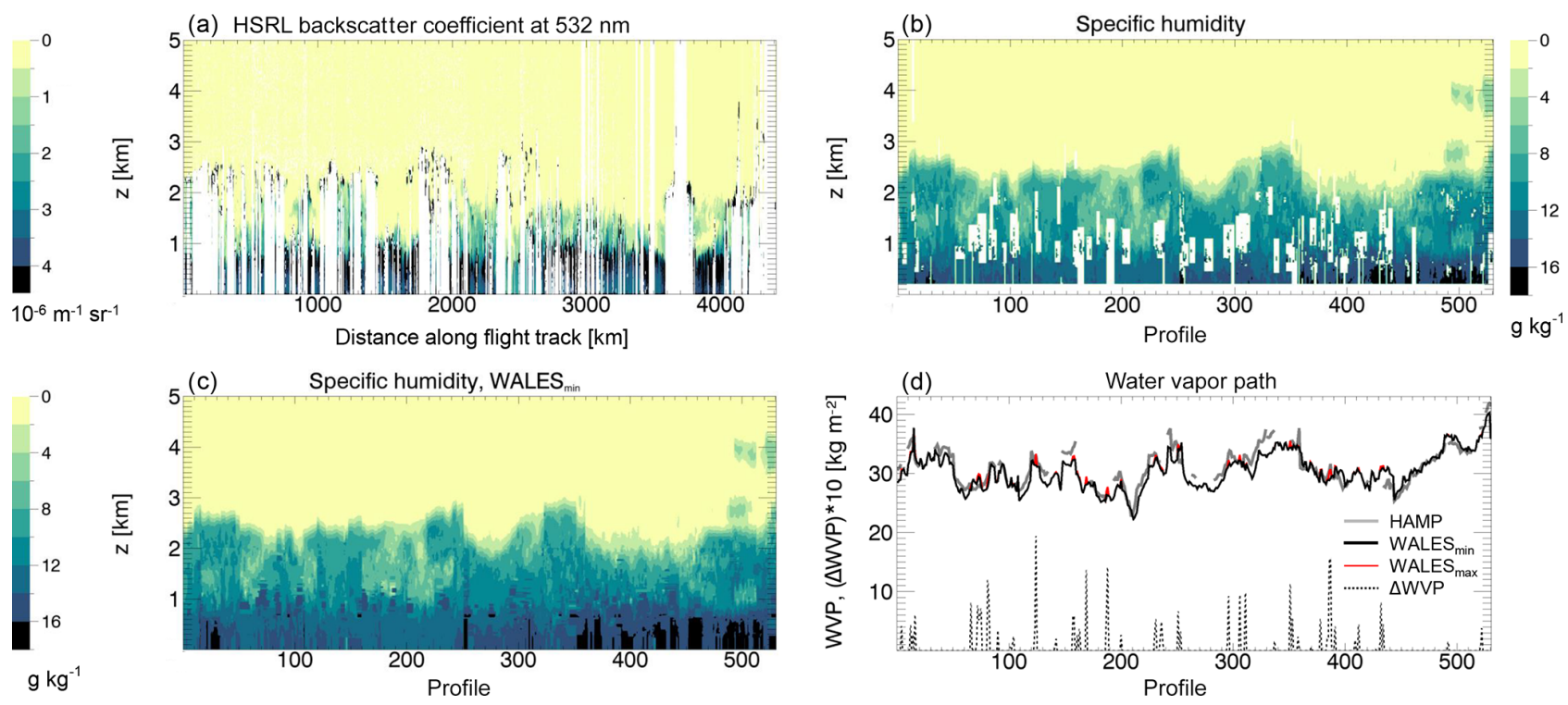

Figure 1. Lidar profiles of the flight on 11 December 2013: (a) atmospheric backscatter for the full flight, (b) specific humidity with lidar gaps, (c) specific humidity of WALES $\max$, and (d) WVP and the difference in WVP between WALES max $_{\text {and WALES }}$ min, $\triangle$ WVP. (bd) show the 531 profiles where more than $50 \%$ of the lidar data within the cloud layer and below are available. The remaining gaps in the original data set in (b) are filled by assuming saturation in clouds, and by nearest-neighbor values elsewhere, resulting in a gap-filled representation in (c) and (d). See text for details. Note that the aspect ratio is $1: 500$ in (a) and $1: 150$ in (b) and (c).

radiometers, whose data are available for NARVAL 1 (Jacob et al., 2019a) and NARVAL 2 (Jacob et al., 2019b). The nadir-viewing HAMP microwave radiometers lack vertical profile information but measure the WVP at $1 \mathrm{~s}$ (that is, $210 \mathrm{~m}$ or $240 \mathrm{~m}$ ) resolution along the HALO flight track even in the presence of shallow clouds (Jacob et al., 2019c). The co-alignment of HAMP with the lidar field of view was checked by comparing the radiometer liquid water path with the lidar cloud backscatter signals, both available at $1 \mathrm{~s}$ resolution. The radiometer signals are interrupted by calibration events. Comparisons with the co-located lidar WVP reveal that those events are independent from the ambient humidity conditions. The radiometer WVP distributions are consequently not biased, except for a slight underrepresentation of the moistest scenes due to signal attenuation which concerns less than $1.5 \%$ of all WVP data.

\section{$2.3 \quad$ ICON}

Simulations are run with ICON (ICOsahedral Nonhydrostatic model; Zängl et al., 2015) with four different grid spacings between $2.5 \mathrm{~km}$ and $300 \mathrm{~m}$ and with two dif- 
ferent model versions: ICON-SRM and ICON-LEM. The ICON-SRM was run with 75 vertical levels and with 2.5 and $1.25 \mathrm{~km}$ nominal horizontal grid spacing. Details of the simulations are described by Klocke et al. (2017). The ICONLEM (Dipankar et al., 2015; Heinze et al., 2017) was run with 150 vertical levels and with 600 and $300 \mathrm{~m}$ nominal horizontal grid spacing. Details of the simulations are described by Stevens et al. (2019). The effective resolution is estimated to be a factor of 6 to 10 larger than the nominal grid spacing (Hansen, 2020). In all simulations the parameterizations for shallow and deep convection, gravity wave drag, and subgrid-scale orography are switched off. The parameterizations for turbulence and microphysics differ between the SRM and the LEM. In addition, the SRM simulations apply a cloud cover parameterization, while the LEM simulations use a binary approach. For this study, we set the LEM cloud fraction to 1 if the liquid water content in a grid box is non-zero and 0 otherwise.

The SRM runs with the coarsest grid spacing of $2.5 \mathrm{~km}$ cover the largest domain, including the entire tropical Atlantic $\left(10.0^{\circ} \mathrm{S}-20.0^{\circ} \mathrm{N}, 68.0^{\circ} \mathrm{W}-15.0^{\circ} \mathrm{E}\right)$. The simulated domain size decreases with increasing resolution, so that the LEM run with the finest grid spacing of $300 \mathrm{~m}$ has the smallest domain, which still covers an area of $800 \mathrm{~km} \times 1600 \mathrm{~km}$ in the western part of the Atlantic $\left(8.0-16.5^{\circ} \mathrm{N}, 60.0-43.5^{\circ} \mathrm{W}\right)$. For the purpose of this study, we do not analyze model output from the full simulation domains of ICON at different resolutions but instead limit the domain analyzed to rectangles around the parts of the flight paths that took place within the smallest simulated domain. Because the flight paths and time periods differ from day to day, the analyzed domains and time periods also differ as given in Table 1 . We analyze all model output in these domains instead of selecting profiles along the flight tracks because convection is not expected to trigger at the exact same location and time in simulations as it does in reality. Using the domain output is consistent with the statistical rather than spatial-temporal approach of this analysis and promotes the robustness of the results.

Initial and boundary conditions for the ICON-SRM $2.5 \mathrm{~km}$ simulations are taken from the European Centre for MediumRange Weather Forecast (ECMWF) reanalysis and vary in time except for the sea surface temperature, which is fixed for each simulation day. The simulations apply a one-way nesting of higher-resolution simulations in low-resolution simulations. The ICON-SRM simulations with $2.5 \mathrm{~km}$ horizontal grid spacing apply an online refinement to $1.25 \mathrm{~km}$ via nesting in the western part of the domain and start at 00:00 UTC for each day of December 2013 and August 2016. They are run forward in time for $36 \mathrm{~h}$. ICON-LEM simulations are initialized and nudged at the lateral boundaries from ICON-SRM and start at 09:00 UTC for selected days to match the flight operations of the NARVAL campaign. They are run forward in time for $27 \mathrm{~h}$. Simulations are analyzed from hourly model output starting earliest at 13:00 UTC (see
Table 1) so that a sufficient spinup period is taken into account.

\section{Case study: covariation of clouds and moisture}

In this section, we use, 11 December 2013, a day of the first NARVAL campaign, for a detailed case study. The aim of the case study is to introduce the central method of this study: the concept of a stretched moisture space. The stretched moisture space is obtained by selective subsampling of the model results and, as such, allows for a fair comparison between lidar data and model results. The case study also illustrates some prominent features of covariation of clouds and moisture, before aggregated seasonal composites enable us to generalize the results to different regimes of water vapor structure in the trades in Sect. 4.

\subsection{Synoptic situation and flight}

We choose 11 December 2013 for a detailed case study for two reasons: first, a regular meander flight pattern allows us to sample a well-defined region thoroughly, which aids comparisons with simulations (Fig. 2). Second, the conditions seem preferential for sampling the humidity space because the flight area includes typical shallow convection over most of the area but also approaches deeper convection with higher humidity towards the south.

The modeled cloud structures have similarities with the observed reflectance from MODIS, showing organized structures of shallow clouds in the northern three quarters of the domain (Fig. 2). With a grid spacing of $2.5 \mathrm{~km}$ these shallow clouds have too broad of a structure compared to observations. With higher resolution the cloud structures, not surprisingly, become finer, but at $300 \mathrm{~m}$ grid spacing the model misses some stratiform outflow from shallow cumulus, giving the shallow convective cloud field a less organized appearance than in satellite observations. In both simulations and in the satellite view the southern quarter of the domain is dominated by a cirrus shield originating from deep convection just south of the domain. This cirrus shield reaches further north in the model than in the satellite observations. Because the deep convective system moves towards the southwest with time and the flight itinerary is following the pattern from north to south, the lidar observations on board the aircraft catch only a small amount of this regime (see Sect. 3.2).

The field of WVP shows more small-scale structure at $300 \mathrm{~m}$ grid spacing than with $2.5 \mathrm{~km}$ but changes less with resolution than the cloud cover does. All simulation show an increase in WVP from north to south and a C shape of low WVP in the northern and central section of the domain. This $\mathrm{C}$ shape in the modeled WVP can be surmised in a reduced presence of clouds in the satellite view but is less well reflected in the modeled cloud cover. 

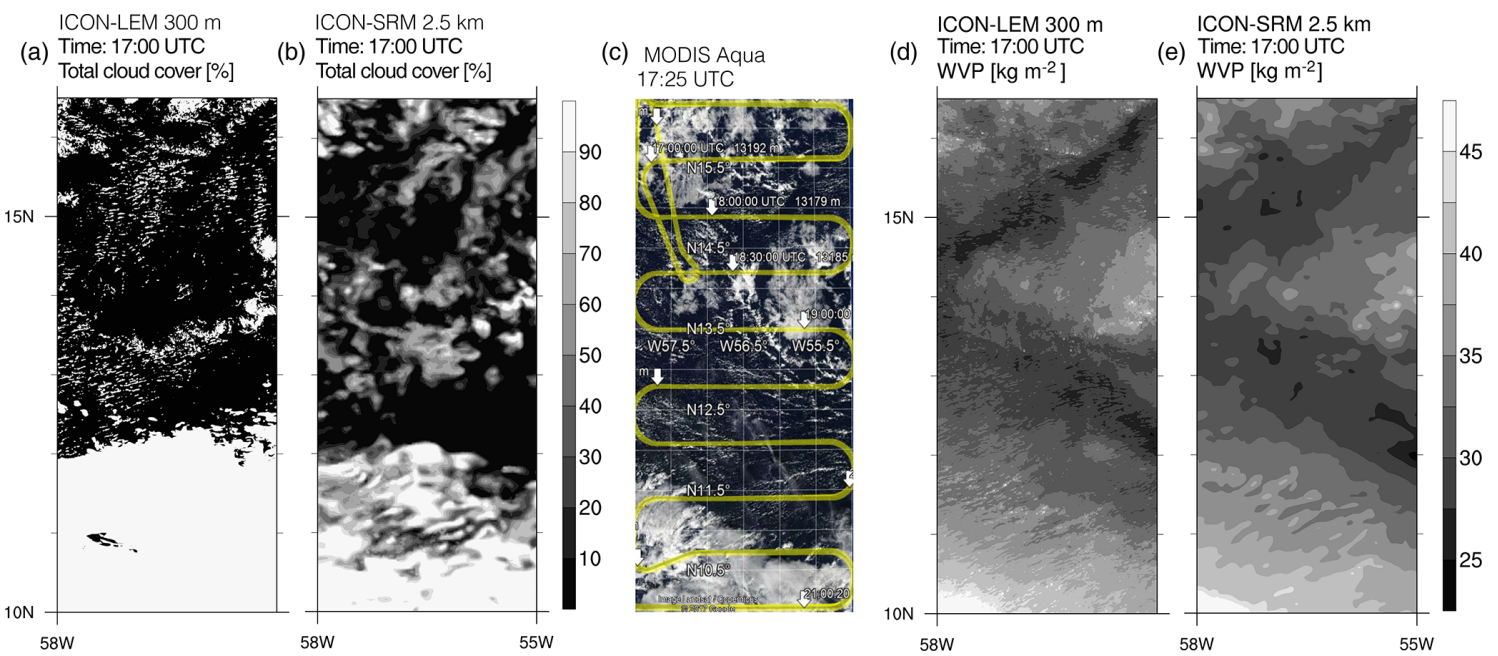

Figure 2. Cloud cover and water vapor path (WVP) in the flight domain on 11 December 2013. Cloud cover at 17:00 UTC from (a) ICONLEM $300 \mathrm{~m}$ and (b) ICON-SRM $2.5 \mathrm{~km}$; (c) MODIS-Aqua corrected reflectance at 17:25 UTC overlaid with the flight path which was flown from north to south (NASA Worldview image, MODIS/Landsat/Copernicus; Google Earth); WVP at 17:00 UTC from (d) ICON-LEM 300 m and (e) ICON-SRM $2.5 \mathrm{~km}$.

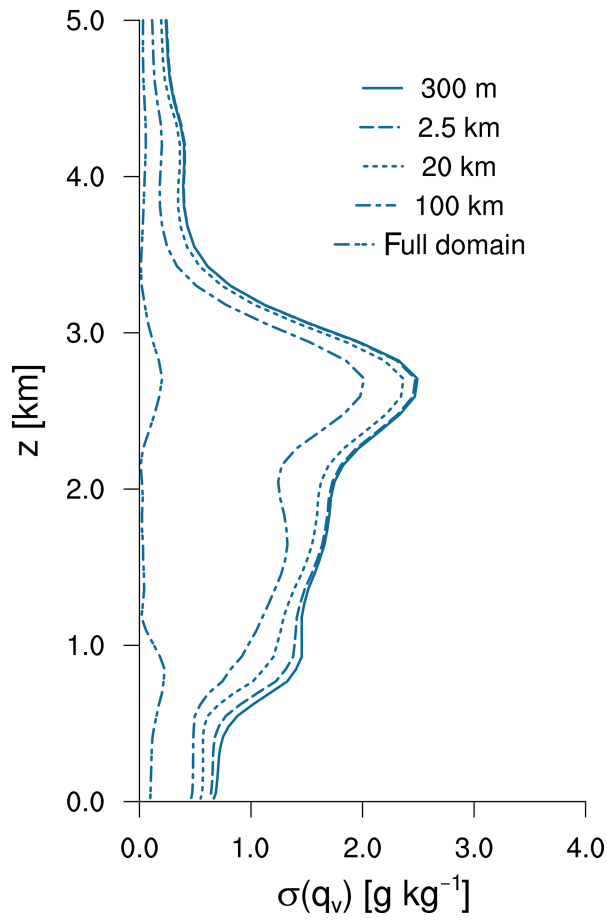

Figure 3. Contribution of different scales to the standard deviation of $q_{\mathrm{v}}$ on 11 December 2013 from ICON-LEM $300 \mathrm{~m}$. Domain and temporal coverage are given in Table 1. Simulations with a grid spacing of $300 \mathrm{~m}$ have been coarsened to squares with side lengths of $2.5 \mathrm{~km} ; 20 \mathrm{~km} ; 100 \mathrm{~km}$; and "full domain", which corresponds to a side length of about $400 \mathrm{~km}$. Both spatial and temporal variability contribute to the standard deviation, except for the full domain, which only shows temporal variability. The cloud layer ranges from cloud base at $z=0.5 \mathrm{~km}$ to the highest cloud tops at $z=3.0 \mathrm{~km}$.
Averaging the results of the ICON-LEM $300 \mathrm{~m}$ simulation on squares of different side length, we analyze how the standard deviation of the water vapor mixing ratio, $q_{\mathrm{v}}$, depends on the considered scales (Fig. 3). The analysis combines spatial and temporal variability, but the contribution from spatial variability predominates (not shown). Coarsegraining the $300 \mathrm{~m}$ LEM results to $2.5 \mathrm{~km}$ does not change the standard deviation considerably. The relative contribution of small scales between $300 \mathrm{~m}$ and $2.5 \mathrm{~km}$ to the standard deviation of $q_{\mathrm{v}}$ is largest near cloud base and in the subcloud layer but generally well below $10 \%$. Even for a side length of $20 \mathrm{~km}$ the relative differences to the native grid spacing of $300 \mathrm{~m}$ are maximum near cloud base $(30 \%)$ but are considerably smaller throughout the cloud layer and above $(<10 \%)$. Because the differences are small, for the remainder of this analysis we show model results and observational data at their native scale (from $300 \mathrm{~m}$ to $2.5 \mathrm{~km}$ ), which aids a direct evaluation of what a simulation is able to catch without artificially reducing information by averaging.

\subsection{Spanning the moisture space}

Because of its stochastic nature, convection is not expected to trigger at the exact same location and time in simulations as it does in reality. To bypass the issue of co-location, we sort water vapor profiles from the driest to the wettest profile and compare simulations and observations in moisture space (Bretherton et al., 2005; Schulz and Stevens, 2018). Comparing simulation results with data from HAMP, this procedure is straightforward because the HAMP data set samples the whole domain well. WALES on the other hand is rapidly attenuated in clouds and saturated in the wettest profiles so that a fair comparison to simulations needs to take into account 
information on which situations WALES is not able to observe. We therefore use HAMP to span the moisture space; to quantify what WALES misses, in particular in the wet regions; and to construct a "stretched moisture space" that enables a fair comparison between WALES and ICON. This method works well during NARVAL because flight patterns were fixed before takeoff and hence measurements along the flight path represent a random sample of the encountered cloud regime. The validity of this method quickly reaches its limits if flight paths are adjusted to preferentially sample a feature of special interest - a trade-off to be aware of for future flight planning (e.g., in view of EUREC ${ }^{4} \mathrm{~A}$; Bony et al., 2017).

We proceed as follows: all available WVP values from HAMP and the ICON simulations at different resolution are sorted from the lowest to the highest value (Fig. 4a). This representation corresponds to the cumulative distribution function of the WVP but with swapped $x$ and $y$ axis compared to the common depiction. Since WALES and HAMP measure the same location at the same time, a co-location between those two instruments is eligible. For 11 December 2013 WALES $_{\text {min }}$ values scatter around HAMP values with a standard deviation of $1.48 \mathrm{~kg} \mathrm{~m}^{-2}\left(1.62 \mathrm{~kg} \mathrm{~m}^{-2}\right.$ for WALES $\left.\mathrm{Wax}_{\max }\right)$, which is consistent with Jacob et al. (2019c). Because WALES measurements attenuate quickly in clouds and for high WVP (Sect. 2), data gaps are not randomly distributed in moisture space but instead preferentially occur where WVP is high: of the driest $10 \%$ of HAMP measurements $48 \%$ have a corresponding measurement from WALES, while for the moistest $10 \%$ of HAMP measurements only $3 \%$ have a corresponding measurement in WALES. To account for this biased sampling of WALES, we randomly select model results and HAMP according to these percentages of WALES counterparts in each $10 \%$ interval. Then we sort all WALES WVP values in ascending order. The resulting new moisture space of all valid WALES data points and those subsampled from ICON and HAMP is effectively stretched in its drier part and compressed in the moister part (Fig. 4b and lower $x$ axis in Fig. 4a). We call this new moisture space the stretched WVP space according to WALES or, in short, the "stretched moisture space". This stretched moisture space enables a fair comparison between WALES and ICON.

In stretched moisture space, the distribution of WVP from ICON simulation results, and WALES and HAMP measurements agree well overall (Fig. 4b, c). The differences between the three observational estimates - HAMP,

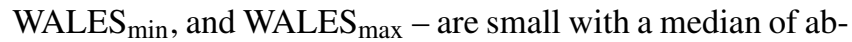
solute difference around $0.6 \mathrm{~kg} \mathrm{~m}^{-2}$ (WALES min $_{\text {Vs. HAMP: }}$ $0.60 \mathrm{~kg} \mathrm{~m}^{-2}$; WALES $\max$ vs. HAMP: $0.56 \mathrm{~kg} \mathrm{~m}^{-2}$ ). The differences in the distributions of WVP between simulations at different grid spacing are much smaller. This possibly reflects the nested modeling approach, which ensures consistent initial and boundary conditions and where domains are nudged with a timescale of $3 \mathrm{~h}$, to ensure that they do not deviate too much in the two-way setup. However, the differ- ences in cloud fraction are considerably larger (see Sect. 3.3), which indicates that the effect of grid spacing in the range of hecto- to kilometer scale is small for the distribution of the WVP.

The small intra-observational and intra-model differences enable a meaningful interpretation of the difference between model and observation. Compared to observations the modeled variability of WVP is too small. The driest model areas are too wet, while the wettest model areas agree well with WALES (Fig. 4c). This underestimation of the variability in WVP can be attributed to the moisture variability that is too low in the cloud layer (see Sect. 3.3). If WVP is not subsampled for valid WALES profiles, there is also a dry model bias for very wet profiles as compared to HAMP (Fig. 4a). Here, the wettest $15 \%$ of HAMP's moisture space seems to be not well represented in the model. Two factors are expected to contribute to this deviation: on 11 December 2013 there is a little change in the flight track near $11^{\circ} \mathrm{N}, 56^{\circ} \mathrm{W}$. This was made to try to fly over the deepest turret of the towering convection and try to drop a sonde through this (Bjorn Stevens, personal communication, 2019). Hence this flight segment is purposely biased to the moistest cell and may contribute to differences in the moist part of the space of Fig. 4a. Also, extending the analyzed model domain to south of $10^{\circ} \mathrm{N}$ decreases this bias, which suggests that the deep convective system on 11 December 2013 is consistently placed too far south in all four simulations (not shown). Because both the deepest turret of the towering convection and in general the moistest profiles towards the south of the domain contain less valid WALES samples than the drier profiles, this feature is much less visible in stretched moisture space and is therefore less important for the remainder of this analysis.

\subsection{Vertical distribution of water vapor and cloud fraction}

With the framework of the stretched moisture space, we can now also analyze the vertical structure of water vapor and cloud fraction by comparing valid WALES profiles with ICON profiles that are subsampled according to percentages of the WALES counterpart. The analysis therefore does not represent the real space as an omniscient observer would see it but only that part that WALES is equipped to measure.

The mean water vapor mixing ratio compares well between WALES and ICON (Fig. 5b). As for the integrated quantity WVP, there is also no dependence on grid spacing in the vertical structure of $q_{\mathrm{v}}$. Compared to WALES the inversion is too high in the model, a feature that is common to all analyzed days in December 2013. Both the observed and the modeled heights of the inversion increase with increasing WVP, but this increase is less pronounced in the simulations (Fig. 6b). For the dry profiles the modeled inversion is also less steep, which implies a less concentrated radiative cooling in the simulations at the cloud layer top with possi- 

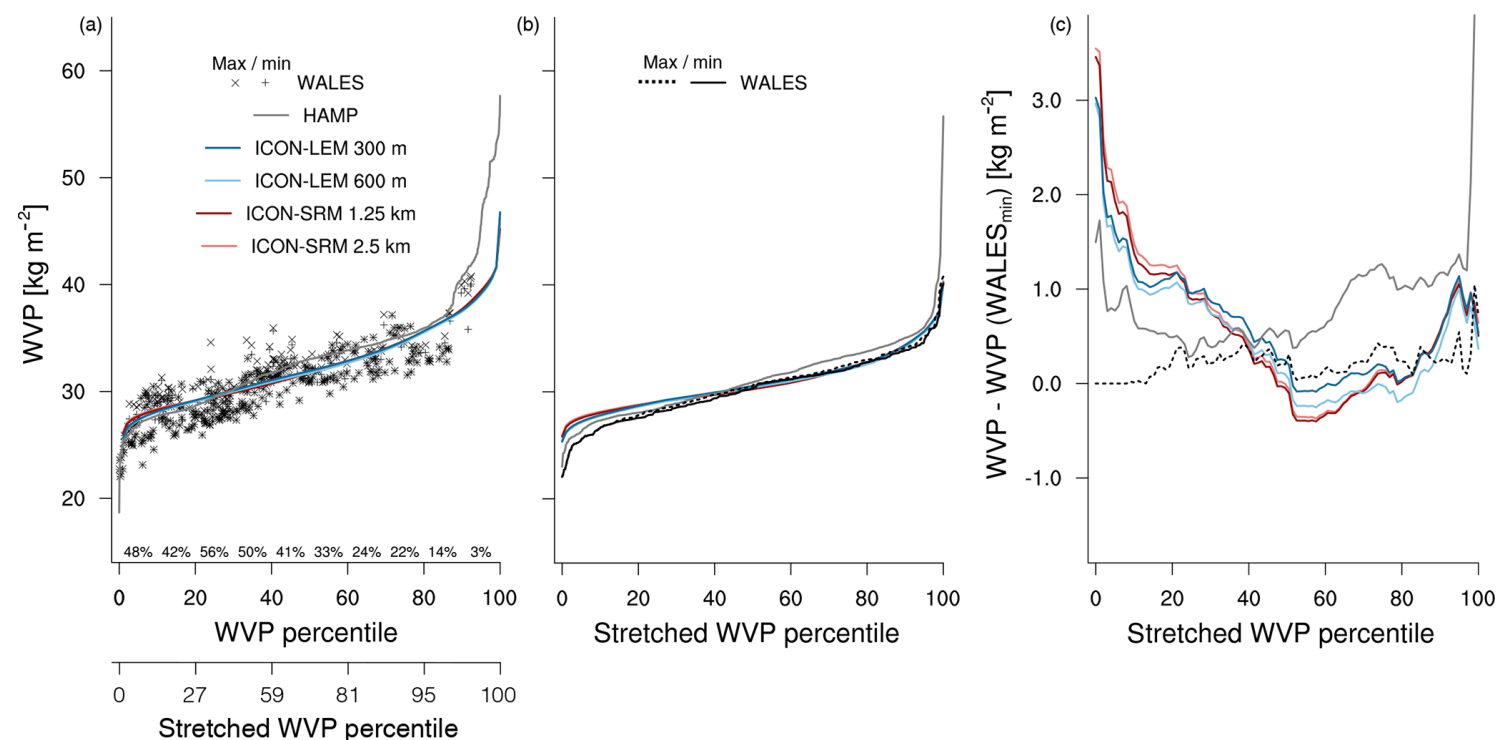

Figure 4. Water vapor path (WVP) on 11 December 2013 in WVP space. (a) ICON simulations and HAMP observations of WVP are sorted by each one's WVP values. WALES data are plotted as co-located with HAMP. Percentages above the $x$ axis tell how many valid WALES measurements have been obtained in each $10 \%$ interval of HAMP's WVP space. (b) ICON results and HAMP data are randomly selected according to the percentages in each $10 \%$ interval resulting in a stretched WVP space, which is also shown as an additional $x$ axis in (a). In (b) WALES data are sorted by their own WVP instead of being co-located with HAMP. (c) As in (b) but for the difference to WALES min. Further details are discussed in the text.
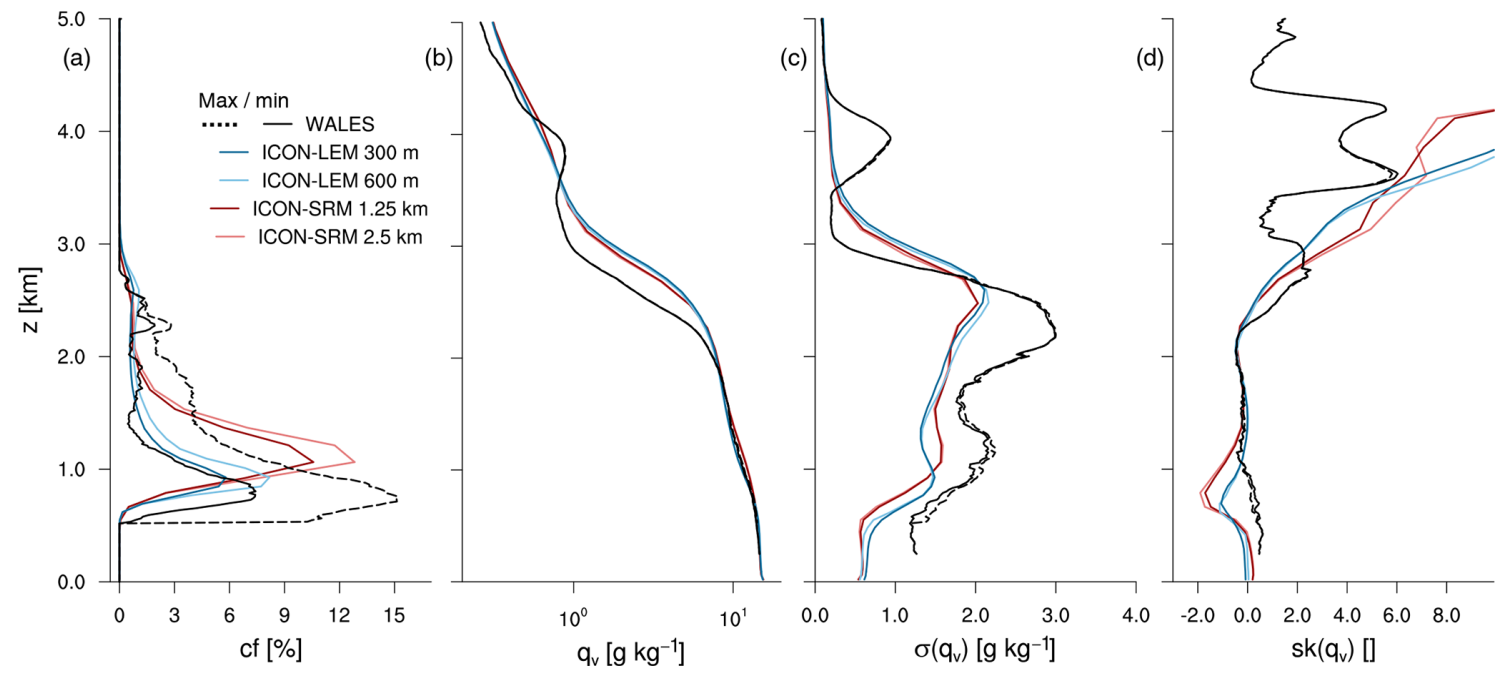

Figure 5. Profiles of (a) cloud fraction; (b) mean water vapor, $q_{\mathrm{v}}$; and its (c) standard deviation and (d) skewness for 11 December 2013 in stretched moisture space as defined in Fig. 4.

ble implications for mesoscale circulations (Naumann et al., 2019).

The higher moments of the water vapor distribution do not agree as well as the mean but still capture the main features and the right magnitude. The two maxima of the standard deviation of $q_{\mathrm{v}}$ in the cloud layer are well captured but are underestimated by the model compared to the observations (Fig. 5c). This is also evident from the change in bias with increasing WVP: in the cloud layer the driest profiles tend to be too moist in the model (Fig. 6c).

The skewness, which is defined as the ratio of the third central moment of the distribution to the $3 / 2$ power of the variance, is reasonably well represented from the middle of the cloud layer up to the cloud layer top (Fig. 5d). Near cloud base the model simulates a negative skewness (that is, few very dry locations associated with cloud-free regions), while the observations indicate slightly positive values (that is, few 

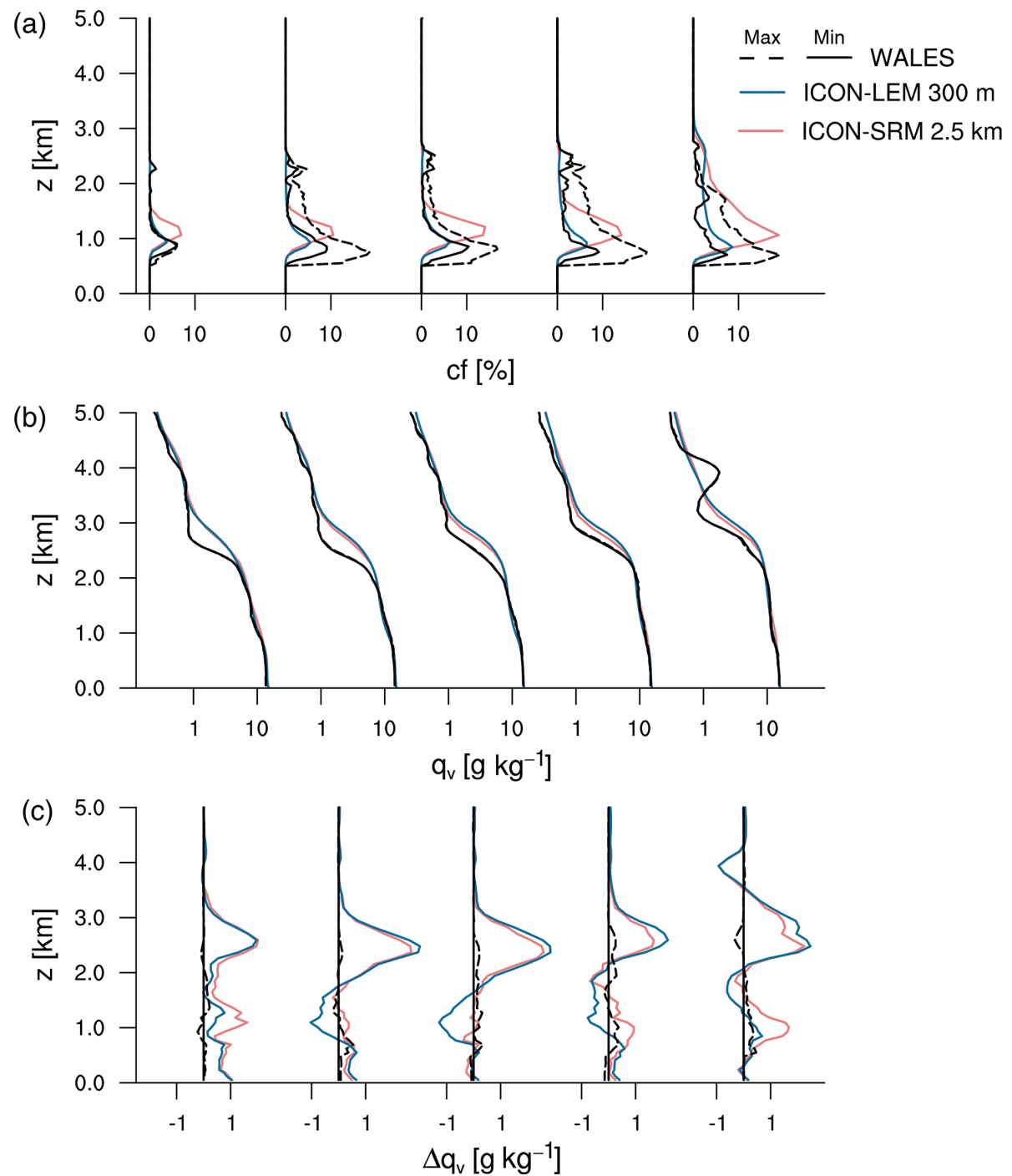

Figure 6. Profiles of (a) cloud fraction, (b) water vapor, and (c) the difference of water vapor to the WALES min estimate for 11 December 2013. Each profile shows the mean for a 20-percentile range of WVP in stretched moisture space from driest profiles on the left to moistest profiles on the right (see Fig. 4). To retain fluctuations due to a limited number of samples, as many profiles as are available from WALES have been randomly subsampled from ICON results (here 531 samples; see Table 1). At a given height level WALES max can be

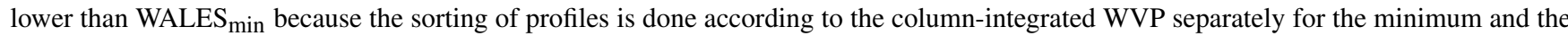
maximum estimate.

very moist locations). This difference in sign between model and observations is also found on 14 and 15 December 2013 but not on the other days (not shown). Above cloud top between 4 and $7 \mathrm{~km}$ the modeled skewness is very large, which is caused by a single deep convective cell near the southwestern corner of the domain that dominates the skewness but has not been sampled by the lidar and is therefore not represented in the observations.

While these properties are also characteristic of other flight days of the NARVAL campaign, a feature that is visible only in the observations on 11 December 2013 is a secondary maximum at $4 \mathrm{~km}$ height (Fig. $5 \mathrm{~b}$ ). This secondary maximum is evident only in the moistest profiles (Fig. 6b), manifests in the southern part of the domain towards the end of the flight (Fig. 1), and is caused by a moist outflow from convectively more active regions. This feature is also reflected in higher values of standard deviation and skewness but is absent in all three moments in the model, which misses the moist outflow (Fig. 5c, d).

For the mean cloud fraction, both uncertainties from observations and sensitivity to model resolution are larger than for $q_{\mathrm{v}}$ (Fig. 5a). Typical cloud sizes obtained from the lidar are around $500 \mathrm{~m}$ (Gutleben et al., 2019) and hence on the order of the grid spacing of the simulations. Because the contribution to overall cloud fraction scales with the size of the clouds, we do not expect the contribution of these small 
clouds to dominate the overall cloud fraction. From WALES the uncertainty in maximum cloud fraction is a factor of 2 (between $7.4 \%$ for WALES $_{\min }$ and $15.2 \%$ for $\mathrm{WALES}_{\max }$ ), but the vertical structure is similar with a clear maximum in cloud fraction near cloud base and few shallow clouds deepening up to $3 \mathrm{~km}$. This structure is also represented well by the simulations, except that the cloud fraction maximum near cloud base is placed too high. We suspect that this upward shift in cloud fraction maximum is linked to the resolution because the shift is stronger for the SRM than the LEM simulations. Another hypothesis, which has recently been developed by Jacob et al. (2020), proposes that slight differences in the autoconversion parameterization in the SRM and LEM might cause differences in the cloud's vertical extent. A further resolution-dependent feature is the value of the maximum cloud fraction, which decreases substantially by a factor of 2 between $12.8 \%$ (ICON-SRM $2.5 \mathrm{~km}$ ) and $5.8 \%$ (ICON-LEM $300 \mathrm{~m}$ ) but is still close to the range of uncertainty given by the observations. Hohenegger et al. (2019) find similar dependencies of cloud fraction on grid spacing between 2.5 and $80 \mathrm{~km}$ and hypothesize that, if horizontal resolution is not sufficient for proper mixing, the boundary layer grows and clouds form higher at colder temperatures, leading also to more cloudiness. The decrease in cloud fraction between the simulations with 600 and $300 \mathrm{~m}$ grid spacing is still substantial and not converged, which is in agreement with idealized modeling studies showing that LEM underestimates cloud fraction when the grid spacing becomes as fine as $50 \mathrm{~m}$ (Vogel et al., 2019).

With increasing WVP the clouds deepen from very shallow cloud tops around $1 \mathrm{~km}$ up to cloud tops around $3 \mathrm{~km}$ both in the simulations and in observations (Fig. 6a). Whether the maximum cloud fraction also increases with increasing WVP is not clear: for $\mathrm{WALES}_{\min }$ the maximum cloud fraction stays about constant, while for WALES $_{\max }$ the maximum cloud fraction increases with increasing WVP. Cloud fraction from the LEM simulations agrees well with the WALES $_{\text {min }}$ estimate, but in the SRM simulations the maximum cloud fraction increases similar to the WALES $_{\max }$ estimate. For features other than the height of the maximum cloud fraction, which is shifted upward in particular in the SRM simulation, it therefore remains unclear for this case study whether the modeled cloud fraction improves with resolution or not. For the season of August 2016 a better representation of cloud fraction with higher resolution becomes apparent, as will be discussed in the next section.

\section{Seasonal composites}

In this section we generalize the results of the case study by applying the same methodology to composites of several research flights that allow us to analyze different regimes of the water vapor structure in the trades. We combine five research flights in December 2013 to one composite case and four research flights from August 2016 for another composite case (Table 1), both of which represent different seasons in the trades. As for the case study in the previous section, we subsample all model results according to the percentages available from WALES in each $10 \%$ bin of WVP for each flight individually. After the subsampling we concatenate the individual flights to obtain the seasonal composite. The composite is thus weighted by the number of valid profiles per flight (which vary from flight to flight; Table 1). The analysis in this section is discussed in the resulting stretched moisture space.

\subsection{Stretched moisture space}

Boreal winter in the northern trades near Barbados is generally characterized by a drier free troposphere compared to boreal summer, which is characterized by more frequent disturbances, a closer proximity of deep convection associated with the ITCZ, and a moister free troposphere (e.g., Stevens et al., 2017). All research flights in December 2013 took place in a period of undisturbed shallow convection (Vial et al., 2019). To analyze whether the chosen research flights characterize a meaningful regime of water vapor structure, we test their representativeness by extending the analyzed period to the ambient days (10 to 21 December 2013) and choosing the mean borders of their domains $\left(12.7-16.5^{\circ} \mathrm{N}\right.$, $\left.57.0-50.4^{\circ} \mathrm{W}\right)$. For December 2013 the research flights represent the extended period very well (Fig. 7a). For August 2016, we extend the period and domain in the same way but for the southern border (11 to 25 August 2016; 13.0$\left.14.3^{\circ} \mathrm{N}, 56.8-48.8^{\circ} \mathrm{W}\right)$. Compared to the mean border, the southern border is shifted $1.5^{\circ} \mathrm{N}$ to avoid inclusion of deep convection from the ITCZ on a few days where it reaches further north. In August 2016, the extended period is several kilograms per square meter moister than the flight period and domain. This difference can be explained by two factors: on several of the flights in August 2016 dry sectors were sought out purposely, biasing the flight periods compared to the extended period (Bjorn Stevens, personal communication, 2019). This illustrates the problem of flying toward specific features, rather than fixing a flight pattern to sample a region evenly (see also Sect. 3.2; Jacob et al., 2019c). In addition, on 20-22 August 2016 the tropical cyclone Fiona runs by north of the domain and brings some very moist air into the domain behind it on 23 August 2016, contributing to a moister extended period. Because the difference between the moist August flights and the dry December flights is considerably larger than the difference between the flight periods and their extended periods, both composite cases can be seen as representative for different regimes. A good representation of the NARVAL flights for their respective season is also found by a comparison with an 8-year-long time series at the Barbados Cloud Observatory in terms of cloud depth and base (Heike Konow, personal communication, 2019). 

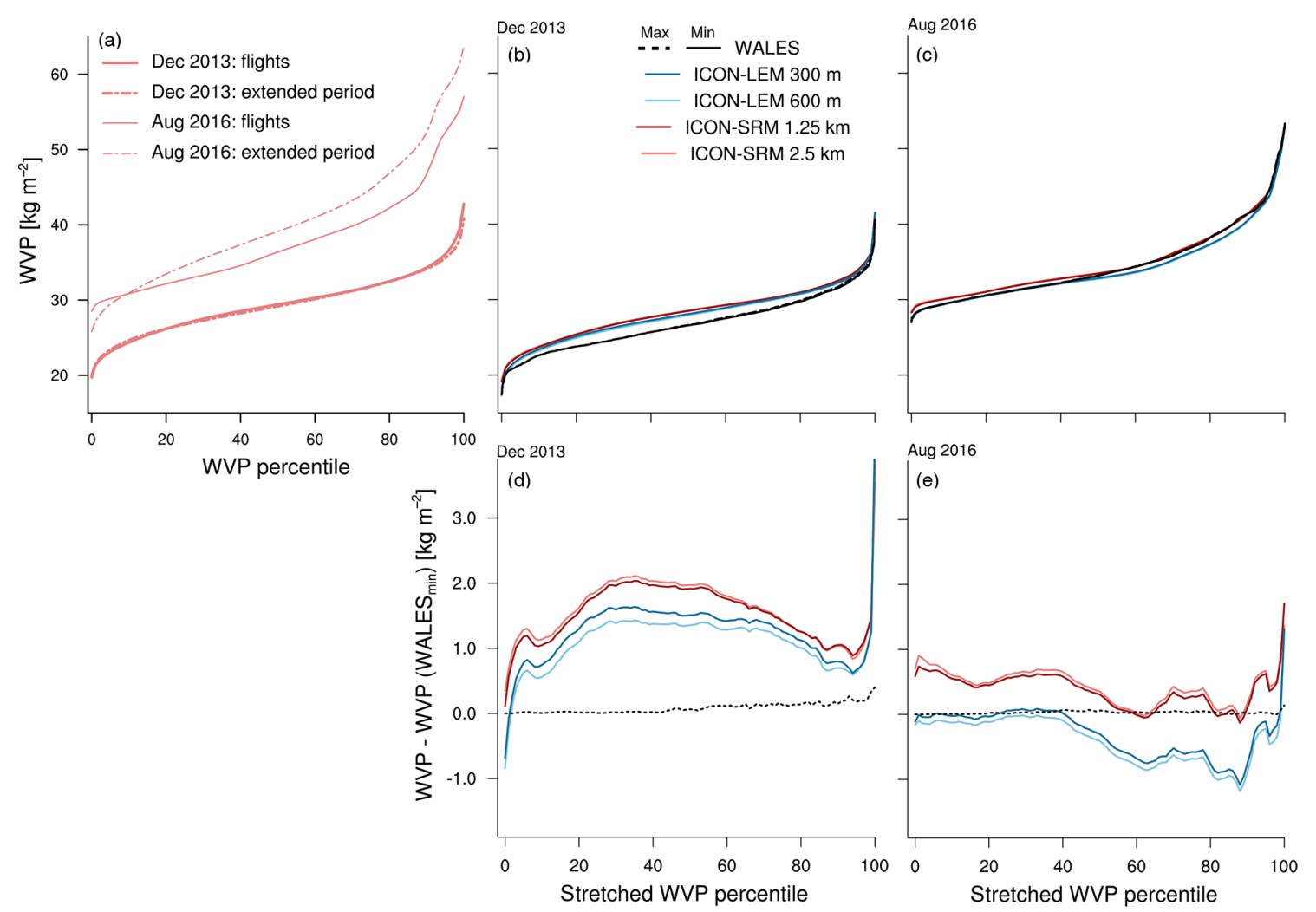

Figure 7. WVP as a function of WVP percentiles (a) for ICON-SRM $2.5 \mathrm{~km}$ and the flight period and domain in December 2013 and August 2016 (see Table 1) as well as for an extended period that includes a longer time period for a domain with mean borders (see text for details); (b) for the flight composite in December 2013; and (c) for the flight composite in August 2016; (d, e) as in (b, c) but for the difference to WALES $\mathrm{Win}_{\min }$.

As for the case study, the stretched distribution of WVP also agrees well between model and observation in the seasonal composites of the flight domains (Fig. 7b-e). The uncertainty in the observational estimate as well as the sensitivity to model resolution is small for both seasons. In December 2013 the model tends to be too moist, with the largest bias up to $2 \mathrm{~kg} \mathrm{~m}^{-2}$ between the 20th and the 60th percentile and a smaller moist bias for the very low and the high WVPs. In August 2016, the agreement is excellent. The LEM results fall almost exactly on the WALES estimate for the lower half of the stretched moisture space, and the SRM results coincide with the WALES estimate in the upper half of the stretched moisture space.

\subsection{Vertical distribution of water vapor and cloud fraction}

For the December composite the vertical distribution of mean water vapor, its first moments, and the cloud fraction is very similar to the case study on 11 December 2013 (Sect. 3). We find good agreement between model and observation both in value and shape of the vertical profiles with a few exceptions (Fig. 8a-d): a too-high model inversion, an underestimation of the standard deviation of $q_{\mathrm{v}}$ in the cloud layer by the model, the model's negative skewness of $q_{\mathrm{v}}$ at cloud base as compared to a positive value in observations, and an upward shift of the modeled height of the maximum cloud fraction. One difference to the case studies of 11 December 2013 is a stronger secondary maximum of cloud fraction near $2 \mathrm{~km}$ height in the simulations with $600 \mathrm{~m}$ to $2.5 \mathrm{~km}$ grid spacing. These small stratiform cloud shields below the inversion are often present in both model and observations (Lamer et al., 2015; Vogel et al., 2019) but are mostly removed from our analysis of the WALES data due to their opacity. The LEM simulations with finest grid spacing $(300 \mathrm{~m})$ are closer to the observations in this case.

Compared to the December composite, the August composite is characterized by a moister free troposphere and a shallower cloud layer $(<2 \mathrm{~km}$, Fig. $8 \mathrm{e}-\mathrm{h})$. This supports the understanding that a moister free troposphere promotes shallower cumuli because both the entrainment of moister air into the boundary layer, which decreases surface fluxes, and a weaker radiative cooling at the cloud layer top lead to a weaker buoyancy excess in clouds compared to their environment, and therefore convection remains shallower (e.g. Nuijens and Siebesma, 2019). 

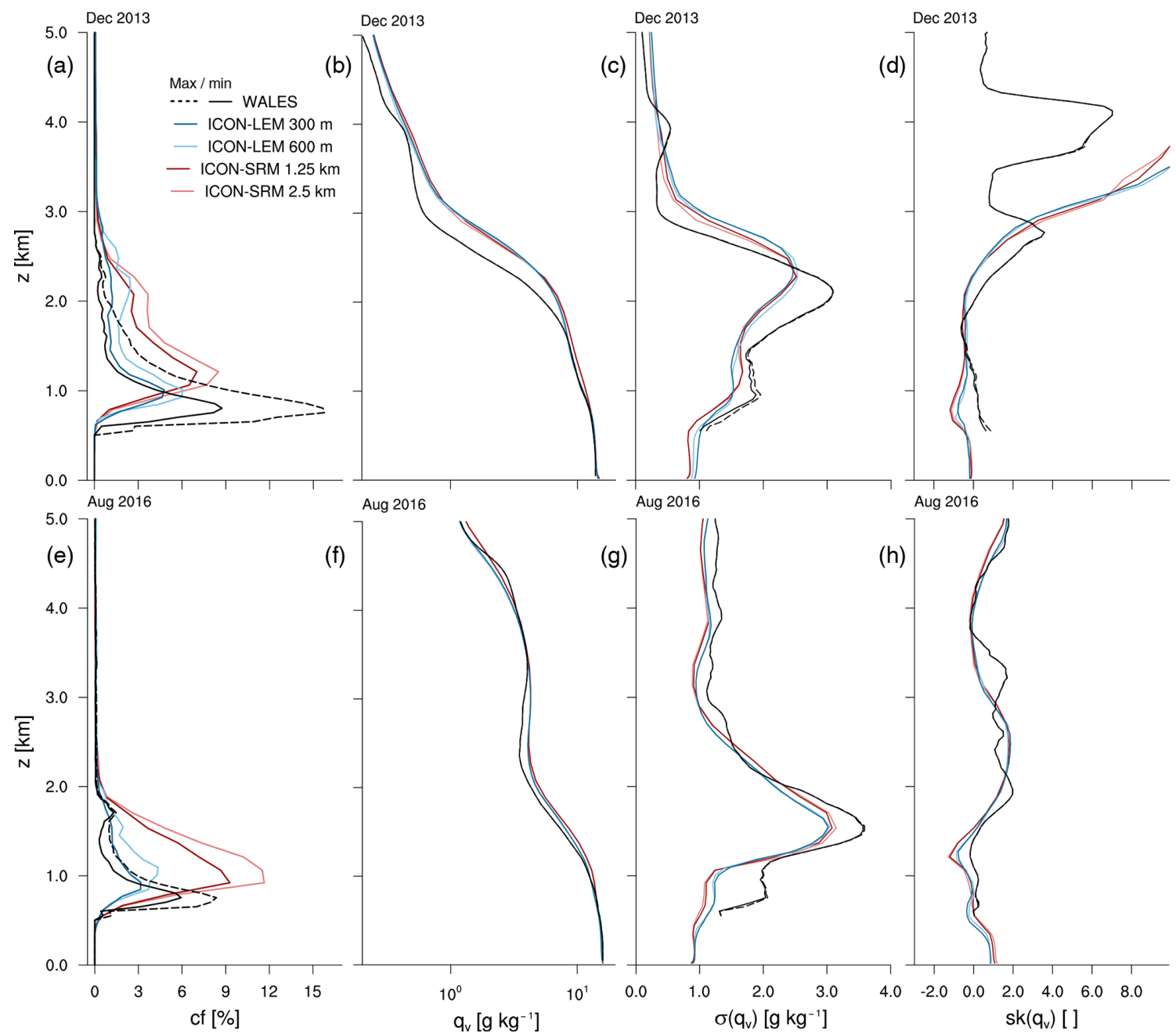

Figure 8. Profiles of (a, e) cloud fraction; (b, f) mean water vapor, $q_{\mathrm{v}}$; and its (c, $\left.\mathbf{g}\right)$ standard deviation and (d, h) skewness for the flight composites of (a-d) December 2013 and (e-h) August 2016 in stretched WVP space as defined in Fig. 7b and c.

For two features there is better agreement between model and observations in the August composite than in the December composite: the moist model bias at the inversion is strongly reduced in August, and model and observations agree on a near-zero skewness of $q_{\mathrm{v}}$ near cloud base. However, the upward shift in the modeled height of the maximum cloud fraction and the underestimation of the standard deviation of $q_{\mathrm{v}}$ in the cloud layer by the model remain. Compared to the SRM simulations at coarser resolution, the LEM simulations are better able to capture the height of the cloud maximum and the amount of cloud fraction except for the cloud base cloud fraction. The SRM simulations clearly overestimate the cloud fraction throughout the cloud layer above cloud base. Because cloud fraction is not converged in the LEM simulations, we expect an underestimation of cloud fraction as grid spacing approaches decameter scale.

A robust feature of the December and the August composite is the observed deepening of the cloud layer with increas- ing WVP from a few hundred meters for low WVP to the top of the inversion for high WVP (at $3 \mathrm{~km}$ in December 2013 and at $2 \mathrm{~km}$ in August 2016; Fig. 9a, d). This deepening is well captured by the simulations across resolution.

A better representation of cloud fraction with higher resolution becomes apparent for the covariation of cloud fraction with WVP. In the August composite the LEM simulations capture the observed increase in cloud fraction from cloudfree to about $10 \%$ (Fig. 9d). However, the transition from cloud-free to low cloud fractions occurs too late in moisture space in the LEM. In contrast the coarse-resolution SRM simulates clearly too much cloud fraction in the driest part of the moisture space, where none is observed, and overestimates cloud fraction at high WVP throughout the cloud layer above cloud base. If the low-level cloud fraction is too large, this increases the radiative cooling of the subcloud layer and can perhaps artificially promote convective self-aggregation too strongly when it is driven by low-level radiative cooling 

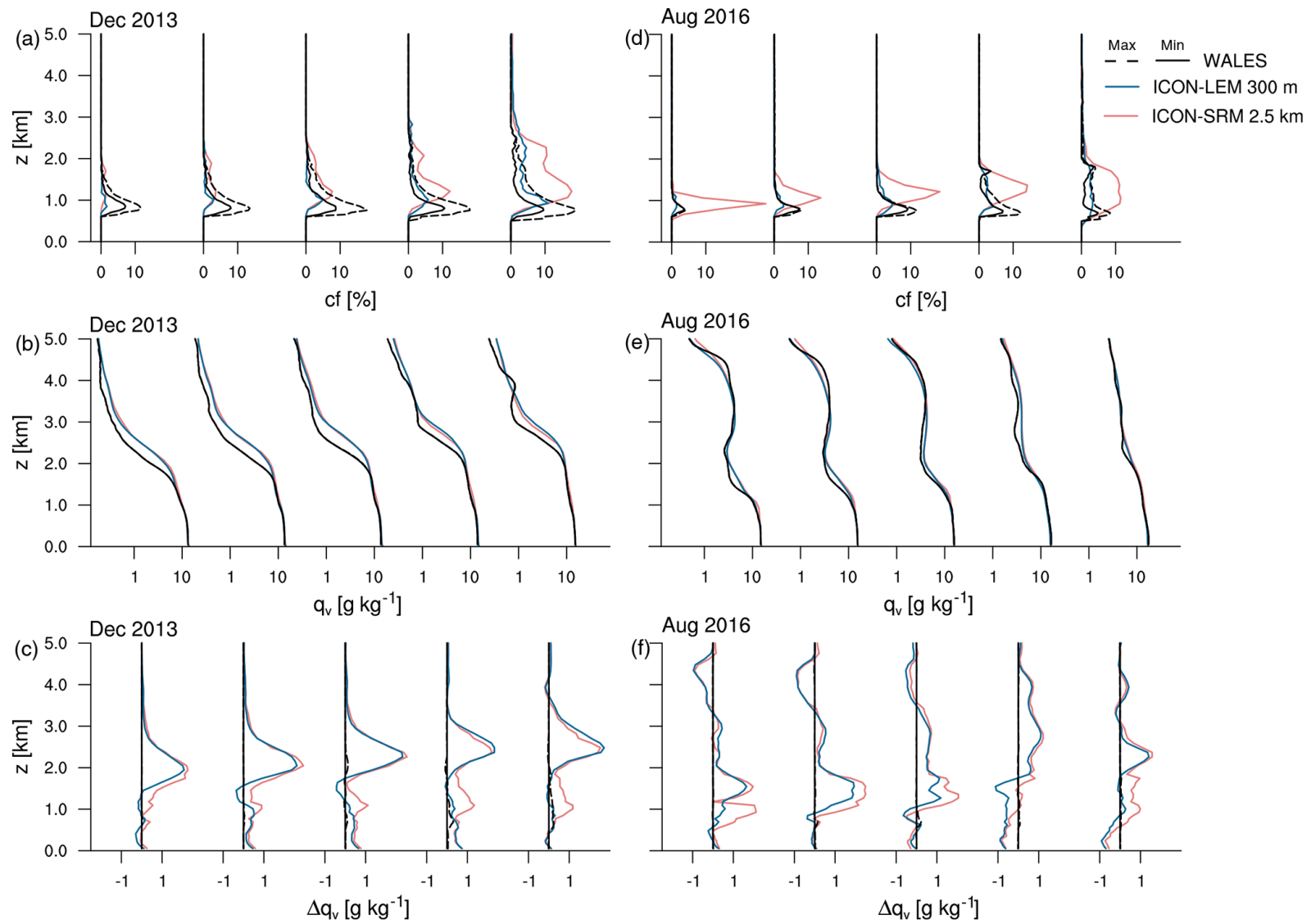

Figure 9. Profiles of $(\mathbf{a}, \mathbf{d})$ cloud fraction, $(\mathbf{b}, \mathbf{e})$ water vapor, and $(\mathbf{c}, \mathbf{f})$ the difference to water vapor WALES min $_{\text {for flight composites }}$ (a-c) December 2013 and (d-f) August 2016. Each profile shows the mean for a 20-percentile range of WVP in stretched moisture space from driest profiles on the left to moistest profiles on the right (see Fig. 7).

outside deep convective regions (e.g., Muller and Held, 2012; Hohenegger and Stevens, 2016; Wing et al., 2017).

Different from the August composite, in the December composite even for the driest part of the moisture space a distinct cloud fraction is observed (Fig. 9a). Neither the SRM nor the LEM is able to capture this cloud regime, but instead they simulate cloud-free conditions. While both observational estimates of cloud fraction agree well for the dry part of the moisture space, the picture is less clear for the moist part of the moisture space. For WALES $\mathrm{max}_{\max }$ the maximum cloud fraction increases with increasing WVP, but for WALES $_{\min }$ it is close to constant. The SRM and LEM results both show increasing cloud fraction with increasing WVP, but due to the uncertainty from the observational estimate we cannot confirm this behavior with WALES. Using groundbased observations that are better able to estimate cloud fraction near cloud base, Nuijens et al. (2013) find that most of the variability in cloud fraction comes from clouds aloft and that clouds near the LCL are rather invariant with time. Although the variability depends on the timescale considered, this and the theory of the cumulus valve mechanism (Neggers et al., 2006; Bellon and Stevens, 2013) seem to be supported by the WALES min $_{\text {in }}$ estimate of a constant cloud fraction near cloud base in moisture space, but not by WALES max $_{\max }$.

Differences in the vertical distribution of water vapor between model and observations are more subtle than those in cloud fraction. The observed rate of increase in inversion height in moisture space is well captured by the simulations (Fig. 9b, e). In both the model and the observations the increase in WVP is mostly accomplished by a deepening of the moist layer and to a lesser extent by increasing moisture in the subcloud layer or above. If the increase in WVP were solely due to a deepening of the moist layer, then the agreement in the deepening rate between observations and simulations would directly follow from their agreement in percentile distribution of WVP (Fig. 7). It can therefore not be seen as a fully independent feature.

In the December composite the simulated inversion is shifted upward independent of WVP, which causes a strong bias around $2 \mathrm{~km}$ height (Fig. 9c). For the December and the August composite the simulated gradients at the inversion are smoother than those observed, a well-known difficulty of simulating inversions in particular if vertical resolution is moderate. (In ICON-LEM the vertical grid spacing is about 
$100 \mathrm{~m}$ at $2 \mathrm{~km}$ height, and in ICON-SRM it is $200 \mathrm{~m}$.) Because the gradient of moisture at the inversion plays an important role for the local radiative fluxes, the weaker gradient implies a less concentrated radiative cooling in the simulations at the cloud layer top. Besides the too-high cloud fraction at kilometer-scale resolution discussed above, the toosmooth moisture gradient at the inversion is another model feature that distorts the interaction between radiation, subsidence, and cloud development.

Model biases in $q_{\mathrm{v}}$ also lead to misrepresentations in modeled cloud fraction. In the August composite in the driest 20 percentiles of moisture space, the SRM is too moist between 500 and $1000 \mathrm{~m}$, that is, where there is too-high cloud fraction. For the mid-range percentiles of moisture space (between the 20th and 60th percentile) the bias in modeled $q_{\mathrm{v}}$ shows a bipolar structure for both SRM and LEM: on the one hand, at the height of the observed cloud maximum the modeled $q_{\mathrm{v}}$ is slightly too low, coinciding with modeled spurious too-low cloud fraction at the observed cloud base. On the other hand, around the inversion the modeled $q_{\mathrm{v}}$ is too high, coinciding with spurious cloud fraction in the SRM at a height where far fewer clouds are observed. We suspect that the latter feature only appears in the SRM simulation and not in the LEM simulation because the SRM applies a cloud fraction parameterization which can produce cloud cover at subsaturation. Taken together, the model smooths $q_{\mathrm{v}}$ in the inversion and thereby puts moisture too high into the inversion region, where it produces clouds in the SRM, and lacks moisture below the inversion, where clouds are observed but not represented in the model.

\section{Conclusions}

In this study, we analyze the distribution of water vapor and clouds in the trades and how their covariation differs in observations and high-resolution models. The NARVAL campaigns, which took place in the northern tropical Atlantic east of Barbados, provide the opportunity to analyze the distribution of water vapor in the trade wind regime of shallow cumulus cloud fields (Stevens et al., 2019). In this study, we analyze five research flights from December 2013 probing the region's dry season and four research flights from August 2016 probing the region's moist season. With a horizontal resolution of $2.5 \mathrm{~km}$, the WALES lidar during the NARVAL campaigns provides accurate measurements of the water vapor distributions primarily in the cloud-free gaps of the shallow cumulus regime. The lidar data are compared with results from nested ICON model runs that are available at four grid spacings from $2.5 \mathrm{~km}$ to $300 \mathrm{~m}$ and that include the area and period of the flight domains.

Because of its stochastic nature, shallow convection is not expected to trigger at the exact same location and time in simulations as it does in reality. To bypass the issue of co-location but retain information on variability, we sort water vapor profiles from the driest to the wettest profile and compare simulations and observations in moisture space (Bretherton et al., 2005; Schulz and Stevens, 2018). Because the signal of the WALES lidar is attenuated rapidly when encountering a cloud and therefore preferentially misses cloudy, high-moisture profiles, information from the HAMP radiometers co-located with the lidar is used to construct a "stretched moisture space" that enables a fair comparison between WALES and ICON.

Across model grid spacing from hecto- to kilometer scale, ICON is able to represent the observed features of the water vapor distribution well. In stretched moisture space it correctly captures the full range of WVP from 20 to $55 \mathrm{~kg} \mathrm{~m}^{-2}$, the main features of the vertical distribution of the first three moments of water vapor, and the variability of water vapor profiles across moisture space. An exception in the vertical distribution is a persistent moist model bias at the trade wind inversion in the dry season, where the model simulates the inversion too high. In both seasons the model tends to smooth the moisture gradient at the inversion too much, which is a known feature of excessive model diffusion and might also be a result of under-resolving shallow convection with low horizontal resolution. In addition, the simulations slightly underestimate the variability of water vapor in the cloud and subcloud layer in both seasons. Both the inversion gradient that is too smooth and the cloud layer variability that is too weak are expected to distort the interaction between radiation, subsidence, and cloud development. The fact that there is little dependence of these features on grid spacing and the general good agreement with observations imply no advantage of hectometer grid spacing over kilometer grid spacing in representing the water vapor distribution in the trade wind regime.

In contrast to water vapor, the modeled cloud fraction strongly depends on grid spacing. While the observed cloud deepening with increasing moisture is captured well across model resolutions, the modeled cloud fraction strongly decreases with increasing grid resolution. In the dry season the observational uncertainty in cloud fraction is too large to make a firm statement. In the wet season, simulations with hectometer grid spacing agree better with observations than simulations with kilometer grid spacing. In particular, the transition from cloud-free to low cloud fraction with increasing moisture, which reflects the close connection between the distribution of water vapor and clouds, is better represented at hectometer resolution. Also, the height of maximum cloud fraction, which is observed just above cloud base, is shifted upward in the model in both seasons but decreases with higher resolution towards the observed values. Although cloud amount and its vertical distribution is compelling at $300 \mathrm{~m}$ grid spacing, it is not converged yet, which is in line with idealized modeling studies showing that LEM underestimates cloud fraction for decameter grid spacing (Vogel et al., 2019). 
In conclusion, we show that high-resolution simulations of the shallow cumulus trade wind regime with kilometerscale grid spacing and realistic boundary conditions are able to capture the characteristics of the lower-tropospheric water vapor distribution well (Heinze et al., 2017; Stevens et al., 2020). They have difficulties, however, in reproducing the observed covariation of water vapor and cloud statistics, which is improved at hectometer resolution. As has been shown for conventional climate models, which apply a convective parameterization at much coarser resolution (e.g., Jiang et al., 2012), this means that capturing the water vapor distribution correctly does not imply that shallow clouds that live at the tail of the water vapor distribution are also well represented. It remains an open question which role such shallow cloud biases in kilometer-scale simulations play for the heat budget of the cloud layer and how they interact with the large-scale environment, for example, in global stormresolving models (Satoh et al., 2019). The latter question of whether and how shallow cloud biases depend on the largescale environment also warrants being pursued further in the light of EUREC ${ }^{4} \mathrm{~A}$, which sets out to measure the distribution of water vapor and clouds in conjunction with the largescale environment (Bony et al., 2017).

Code and data availability. Model results and observational data used in this study are published in different peer-reviewed papers, as follows: ICON-SRM NARVAL 1+2 - Klocke et al. (2017); ICON-LEM NARVAL 1+2 - Stevens et al. (2019); WALES NARVAL 1 - Kiemle et al. (2017); WALES NARVAL 2 Gutleben et al. (2019); HAMP NARVAL 1+2 - Jacob et al. (2019c), https://doi.org/10.26050/WDCC/HALO_measurements_5 (Jacob et al., 2019a), and https://doi.org/10.26050/WDCC/HALO_ measurements_6 (Jacob et al., 2019b).

Author contributions. AKN and CK developed the idea of the study and carried out the analysis for this paper. AKN took the leading role in writing the paper with input from CK.

Competing interests. The authors declare that they have no conflict of interest.

Special issue statement. This article is part of the special issue "Tropospheric profiling (ISTP11) (AMT/ACP inter-journal SI)". It is not associated with a conference.

Acknowledgements. We thank Bjorn Stevens for inspiring discussions and in particular for his idea to include radiometer data in this study. We also thank Marek Jacob for kindly providing the HAMP data, Silke Gross and Martin Wirth for the WALES data, and Daniel Klocke and Matthias Brück for the ICON results used in this study. We thank the editor, Andreas Richter, and three anonymous reviewers for their helpful comments. The data used in this publication were gathered in the NARVAL 1 and 2 campaigns, and WALES data are made available through the German Aerospace Center (DLR). NARVAL was funded with support of the Max Planck Society, the German Research Foundation (DFG, project HALO-SPP 1294), the European Research Council (ERC), the German Meteorological Weather Service (DWD), and DLR. Primary data and scripts used in the analysis and other supplementary information that may be useful in reproducing the authors' work are archived by the Max Planck Institute for Meteorology and can be obtained by contacting publications@mpimet.mpg.de.

Financial support. During part of this research Ann Kristin Naumann was funded as part of the Hans-Ertel Centre for Weather Research. This research network of universities, research institutes, and the Deutscher Wetterdienst is funded by the BMVI (Federal Ministry of Transport and Digital Infrastructure). Ann Kristin Naumann also received funding from the Deutsche Forschungsgemeinschaft (DFG, German Research Foundation) under Germany's Excellence Strategy - EXC 2037 "Climate, Climatic Change, and Society” (project number 390683824).

The article processing charges for this open-access publication were covered by the Max Planck Society.

Review statement. This paper was edited by Andreas Richter and reviewed by three anonymous referees.

\section{References}

Bauer, P., Thorpe, A., and Brunet, G.: The quiet revolution of numerical weather prediction, Nature, 525, 7567, 2015.

Bellon, G. and Stevens, B.: Time scales of the trade wind boundary layer adjustment, J. Atmos. Sci., 70, 1071-1083, 2013.

Bony, S., Stevens, B., Ament, F., Crewell, S., Delanoe, J., Farrell, D., Flamant, C., Gross, S., Hirsch, L., Mayer, B., Nuijens, L., Ruppert Jr., J. H., Sandu, I., Siebesma, P., Speich, S., Szczap, F., Vogel, R., Wendisch, M., and Wirth, M.: EUREC ${ }^{4}$ A: a field campaign to elucidate the couplings between clouds, convection and circulation, Surv. Geophys., 38, 1529-1568, 2017.

Bretherton, C. S., Peters, M. E., and Back, L. E.: Relationships between water vapor path and precipitation over the tropical oceans, J. Climate, 17, 1517-1528, 2004.

Bretherton, C. S., Blossey, P. N., and Khairoutdinov, M.: An energybalance analysis of deep convective self-aggregation above uniform SST, J. Atmos. Sci., 62, 4273-4292, 2005.

Dipankar, A., Stevens, B., Heinze, R., Moseley, C., Zängl, G., Giorgetta, M., and Brdar, S.: Large eddy simulation using the general circulation model ICON, J. Adv. Model. Earth Sy., 7, 963-986, 2015.

Gutleben, M., Groß, S., and Wirth, M.: Cloud macro-physical properties in Saharan-dust-laden and dust-free North Atlantic trade wind regimes: a lidar case study, Atmos. Chem. Phys., 19, 10659-10673, https://doi.org/10.5194/acp-19-10659-2019, 2019.

Hansen, A.: New techniques for ultra-high-resolution circulation model evaluation, PhD thesis, Universität Hamburg, 2020. 
Heinze, R., Dipankar, A., Henken, C., Moseley, C., Sourdeval, O., Trömel, S., Xie, X., Adamidis, P., Ament, F., Baars, H., Barthlott, C., Behrendt, A., Blahak, U., Bley, S., Brdar, S., Brueck, M., Crewell, S., Deneke, H., Girolamo, P., Evaristo, R., Fischer, J., Frank, C., Friederichs, P., Göcke, T., Gorges, K., Hande, L., Hanke, M., Hansen, A., Hege, H.-C., Hoose, C., Jahns, T., Kalthoff, N., Klocke, D., Kneifel, S., Knippertz, P., Kuhn, A., van Laar, T., Macke, A., Maurer, V., Mayer, B., Meyer, C., Muppa, S., Neggers, R., Orlandi, E., Pantillon, F., Pospichal, B., Röber , N., Scheck, L., Seifert, A., Seifert, P., Senf, F., Siligam, P., Simmer, C., Steinke, S., Stevens, B., Wapler, K., Weniger, M., Wulfmeyer, V., Zängl, G., Zhang, D., and Quaas, J.: Large-eddy simulations over Germany using ICON: a comprehensive evaluation, Q. J. Roy. Meteor. Soc., 143, 69-100, 2017.

Hohenegger, C. and Stevens, B.: Coupled radiative convective equilibrium simulations with explicit and parameterized convection, J. Adv. Model. Earth Syst., 8, 1468-1482, https://doi.org/10.1002/2016MS000666, 2016.

Hohenegger, C., Kornblueh, L., Klocke, D., Becker, T., Cioni, G., Engels, J. F., Schulzweida, U., and Stevens, B.: Climate statistics in global simulations of the atmosphere, from 80 to $2.5 \mathrm{~km}$ grid spacing, in review, 2019.

Holloway, C. E. and Neelin, J. D.: Moisture vertical structure, column water vapor, and tropical deep convection, J. Atmos. Sci., 66, 1665-1683, 2009.

Jacob, M., Ament, F., Gutleben, M., Konow, H., Mech, M., Wirth, M., and Crewell, S.: Liquid water path and integrated water vapor over the tropical Atlantic during NARVAL-South, https://doi.org/10.26050/WDCC/HALO_measurements_5, 2019a.

Jacob, M., Ament, F., Gutleben, M., Konow, H., Mech, M., Wirth, M., and Crewell, S.: Liquid water path and integrated water vapor over the tropical Atlantic during NARVAL2, https://doi.org/10.26050/WDCC/HALO_measurements_6, 2019b.

Jacob, M., Ament, F., Gutleben, M., Konow, H., Mech, M., Wirth, M., and Crewell, S.: Investigating the liquid water path over the tropical Atlantic with synergistic airborne measurements, Atmos. Meas. Tech., 12, 3237-3254, https://doi.org/10.5194/amt12-3237-2019, 2019c.

Jacob, M., Kollias, P., Ament, F., Schemann, V., and Crewell, S.: Multi-layer Cloud Conditions in Trade Wind Shallow Cumulus Confronting Models with Airborne Observations, Geosci. Model Dev. Discuss., https://doi.org/10.5194/gmd-2020-14, in review, 2020

Jiang, J., Su, H., Zhai, C., Perun, V. S., Del Genio, A., Nazarenko, L. S., Donner, L. J., Horowitz, L. W., Seman, C., Cole, J., Gettelman, A., Ringer, M. A., Rotstayn, L., Jeffrey, S., Wu, T., Brient, F., Dufresne, J., Kawai, H., Koshiro, T., Watanabe, M., LÉcuyer, T. S., Volodin, E. M., Iversen, T., Drange, H., Mesquita, M. D. S., Read, B., Waters, J. W., Tian, B.,Teixeira, J., and Stephens, G.: Evaluation of cloud and water vapor simulations in CMIP5 climate models using NASA "A-Train" satellite observations, J. Geophys. Res.-Atmos., 117, D14105, https://doi.org/10.1029/2011JD017237, 2012.

Keil, C., Röpnack, A., Craig, G. C., and Schumann, U.: Sensitivity of quantitative precipitation forecast to height dependent changes in humidity, Geophys. Res. Lett., 35, L09812, https://doi.org/10.1029/2008GL033657, 2008.
Kiemle, C., Groß, S., Wirth, M., and Bugliaro, L.: Airborne lidar observations of water vapor variability in tropical shallow convective environment, Surv. Geophys., 38, 1425-1443, https://doi.org/10.1007/s10712-017-9431-5, 2017.

Klocke, D., Brueck, M., Hohenegger, C., and Stevens, B.: Rediscovering the Doldrums in Cloud Resolving Simulations of the Tropical Atlantic, Nat. Geosci., 10, 891-896, https://doi.org/10.1038/s41561-017-0005-4, 2017.

Konow, H., Jacob, M., Ament, F., Crewell, S., Ewald, F., Hagen, M., Hirsch, L., Jansen, F., Mech, M., and Stevens, B.: A unified data set of airborne cloud remote sensing using the HALO Microwave Package (HAMP), Earth Syst. Sci. Data, 11, 921-934, https://doi.org/10.5194/essd-11-921-2019, 2019.

Lamer, K., Kollias, P., and Nuijens, L.: Observations of the variability of shallow trade wind cumulus cloudiness and mass flux, J. Geophys. Res.-Atmos., 120, 6161-6178, 2015.

Mauritsen, T. and Stevens, B.: Missing iris effect as a possible cause of muted hydrological change and high climate sensitivity in models, Nat. Geosci., 8, 346-351, 2015.

Mauritsen, T., Stevens, B., Roeckner, E., Crueger, T., Esch, M., Giorgetta, M., Haak, H., Jungclaus, J., Klocke, D., Matei, D., Mikolajewicz, U., Notz, D., Pincus, R., Schmidt, H., and Tomassini, L.: Tuning the climate of a global model, J. Adv. Model. Earth Sy., 4, M00A01, https://doi.org/10.1029/2012MS000154, 2012.

Muller, C. and Bony, S.: What favors convective aggregation and why?, Geophys. Res. Lett., 42, 5626-5634, 2015.

Muller, C. J. and Held, I. M.: Detailed investigation of the selfaggregation of convection in cloud-resolving simulations, J. Atmos. Sci., 69, 2551-2565, 2012.

Naumann, A. K., Stevens, B., and Hohenegger, C.: A moist conceptual model for the boundary layer structure and radiatively driven shallow circulations in the trades, J. Atmos. Sci., 76, 1289-1306, https://doi.org/10.1175/JAS-D-18-0226.1, 2019.

Neggers, R., Stevens, B., and Neelin, J. D.: A simple equilibrium model for shallow-cumulus-topped mixed layers, Theor. Comp. Fluid Dyn., 20, 305-322, 2006.

Nehrir, A. R., Kiemle, C., Lebsock, M. D., Kirchengast, G., Buehler, S. A., Löhnert, U., Liu, C.-L., Hargrave, P. C., BarreraVerdejo, M., and Winker, D. M.: Emerging technologies and synergies for airborne and space-based measurements of water vapor profiles, Surv. Geophys., 38, 1445-1482, 2017.

Nuijens, L. and Siebesma, A. P.: Boundary Layer Clouds and Convection over Subtropical Oceans in Our Current and in a Warmer Climate, Current Climate Change Reports, 5, 80-94, https://doi.org/10.1007/s40641-019-00126-x, 2019.

Nuijens, L., Stevens, B., and Siebesma, A. P.: The environment of precipitating shallow cumulus convection, J. Atmos. Sci., 66, 1962-1979, 2009.

Nuijens, L., Serikov, I., Hirsch, L., Lonitz, K., and Stevens, B.: The distribution and variability of low-level cloud in the North Atlantic trades, Q. J. Roy. Meteor. Soc., 140, 2364-2374, 2013.

Pierrehumbert, R. T.: Thermostats, radiator fins, and the local runaway greenhouse, J. Atmos. Sci., 52, 1784-1806, 1995.

Ramanathan, V. and Collins, W.: Thermodynamic regulation of ocean warming by cirrus clouds deduced from observations of the 1987 El Nino, Nature, 351, 27-32, https://doi.org/10.1038/351027a0, 1991. 
Satoh, M., Stevens, B., Judt, F., Khairoutdinov, M., Lin, S.J., Putman, W. M., and Düben, P.: Global Cloud-Resolving Models, Current Climate Change Reports, 5, 172-184, https://doi.org/10.1007/s40641-019-00131-0, 2019.

Schulz, H. and Stevens, B.: Observing the tropical atmosphere in moisture space, J. Atmos. Sci., 75, 3313-3330, https://doi.org/10.1175/JAS-D-17-0375.1, 2018.

Stevens, B., Brogniez, H., Kiemle, C., Lacour, J.-L., Crevoisier, C., and Kiliani, J.: Structure and dynamical influence of water vapor in the lower tropical troposphere, Surv. Geophys., 38, 13711397, 2017.

Stevens, B., Ament, F., Bony, S., Crewell, S., Ewald, F., Gross, S., Hansen, A., Hirsch, L., Jacob, M., Kölling, T., Konow, H., Mayer, B., Wendisch, M., Wirth, M., Wolf, K., Bakan, S., BauerPfundstein, M., Brueck, M., Delanoë, J., Ehrlich, A., Farrell, D., Forde, M., Gödde, F., Grob, H., Hagen, M., Jäkel, E., Jansen, F., Klepp, C., Klingebiel, M., Mech, M., Peters, G., Rapp, M., Wing, A., and Zinner, T.: A high-altitude long-range aircraft configured as a cloud observatory - the NARVAL expeditions. Bulletin of the American Meteorological Society, 100, 1061-1077, https://doi.org/10.1175/BAMS-D-18-0198.1, 2019.

Stevens, B., Acquistapace, C., Hansen, A., Heinze, R., Klinger, C.,Klocke, D., Rybka, H., Schubotz, W., Windmiller, J., Adamidis, P., Arka, I.,Barlakas, V., Biercamp, J., Brueck, M., Brune, S., Buehler, S. A., Burkhardt, U.,Cioni, G., Costa-Suròs, M., Crewell, S., Crüger, T., Deneke, H., Friederichs, P., Henken, C. C., Hohenegger, C., Jacob, M., Jakub, F., Kalthoff, N., Köhler, M., van Laar, T. W., Li, P., Löhnert, U., Macke, A., Madenach, N., Mayer, B., Nam, C., Naumann, A. K., Peters, K., Poll, S., Quaas, J., Röber, N., Rochetin, N., Scheck, L., Schemann, V., Schnitt, S., Seifert, A., Senf, F., Shapkalijevski, M., Simmer, C., Singh, S., Sourdeval, O., Spickermann, D.,Strandgren, J., Tessiot, O., Vercauteren, N., Vial, J., Voigt, A., and Zängl, G.: The added value of large-eddy and storm-resolving models for simulating clouds and precipitation, J. Meteor. Soc. Japan, 98, Special Edition on DYAMOND: The DYnamics of the Atmospheric general circulation Modeled On Non-hydrostatic Domains, https://doi.org/10.2151/jmsj.2020-021, 2020.
Vial, J., Bony, S., Stevens, B., and Vogel, R.: Mechanisms and model diversity of trade-wind shallow cumulus cloud feedbacks: a review, Surv. Geophys., 38, 159-181, 2017.

Vial, J., Vogel, R., Bony, S., Stevens, B., Winker, D. M., Cai, X.,Hohenegger, C., Naumann, A. K., and Brogniez, H.: A new look at the daily cycle of tradewind cumuli, J. Adv. Model. Earth Syst., 11, 3148-3166, https://doi.org/10.1029/2019MS001746, 2019.

Vogel, R., Nuijens, L., and Stevens, B.: Influence of deepening and mesoscale organization of shallow convection on stratiform cloudiness in the downstream trades, Q. J. Roy. Meteorol. Soc., 146, 174-185, https://doi.org/10.1002/qj.3664, 2020.

Wing, A. A., Emanuel, K., Holloway, C. E., and Muller, C.: Convective self-aggregation in numerical simulations: A review, in: Shallow Clouds, Water Vapor, Circulation, and Climate Sensitivity, Springer, 1-25, 2017.

Wirth, M., Fix, A., Mahnke, P., Schwarzer, H., Schrandt, F., and Ehret, G.: The airborne multi-wavelength water vapor differential absorption lidar WALES: system design and performance, Appl. Phys., 96, 201-213, https://doi.org/10.1007/s00340-0093365-7, 2009.

Zängl, G., Reinert, D., Rípodas, P., and Baldauf, M.: The ICON (ICOsahedral Non-hydrostatic) modelling framework of DWD and MPI-M: Description of the non-hydrostatic dynamical core, Q. J. Roy. Meteor. Soc., 141, 563-579, 2015. 